\title{
BACTERIOLOGICAL OBSERVATIONS IN A MECHANI- CALLY VENTILATED EXPERIMENTAL WARD AND IN TWO OPEN-PLAN WARDS
}

\author{
W. WhYTE *, J. G. R. HowIE AND J. E. EAKIN \\ University Department of Bacteriology and Immunology, \\ Western Infirmary, Glasgow
}

THE practice of building subdivided ward units of complex design rather than open-plan wards has increased greatly in recent years. Mechanical ventilation equipment, until a few years ago used only in operating-theatre suites, is now often installed in other parts of the hospital to provide a comfortable environment and to ensure an adequate supply of fresh air to the internal rooms of large and complex buildings. Both ward-subdivision and mechanical ventilation may also have a part to play in reducing cross-infection.

The principles laid down by earlier workers who studied hospital infection had a major influence on current practice in the design of operating theatres (Colebrook et al., 1944; Bourdillon and Colebrook, 1946; Lowbury, 1954; Blowers et al., 1955; Shooter et al., 1956), and these principles have recently been applied to the design of other parts of the hospital.

Several groups of workers have considered the effectiveness of the design of ward units in reducing the cross-infection risk. Williams et al. (1962) at St Bartholomew's Hospital carried out an investigation in which patients in one ward who had staphylococcal lesions or were carriers of tetracyclineresistant Staphylococcus aureus were isolated in cubicles. The post-operative staphylococcal sepsis rate in this ward did not differ significantly from the rate in other wards in which isolation was not practised. However, patients in the ward with isolation facilities appeared to become nasal carriers of tetracycline-resistant Staph. aureus more slowly than those in the non-isolation wards, and there was also some evidence that the epidemic spread of Staph. aureus was less in the isolation ward than in the open ward. Similar work at St Bartholomew's Hospital by Shooter et al. (1963) showed that little is to be gained by protecting pre-operative patients from hospital infection by the division of a ward in two by a ceiling-high partition.

More recent work by Williams (1967) and Lidwell et al. (1966) in subdivided wards indicated that the acquisition of Staph. aureus occurred at a lower rate than had previously been observed in the open wards. Parker et al. (1965) studied an infectious disease ward where patients were barrier-nursed in separate cubicles that opened on to a veranda. In this case there was little if any transference of Staph. aureus from patient to patient.

Received 19 Dec. 1968; accepted 28 Feb. 1969.

* Present address : Building Services Research Unit, University of Glasgow.

J. MED. MICROBIOL.-VOL. 2 (1969) 
Steingold et al. (1963) reported that there was a reduction in the incidence of infection after the introduction of mechanical ventilation into a ward, but this observation has yet to be repeated.

These and similar studies are clearly relevant to the management of patients subjected to renal transplantation with immunosuppressive therapy in specialised units (Woodruff et al., 1968). These units are clearly not designed for general medical or surgical use, and there is no clear indication whether the partial isolation of patients and the control of ventilation would lead to a reduction of the cross-infection risk that would justify the expense of providing the additional facilities.

To study air conditioning and the subdivision of wards in relation to crossinfection, the Hairmyres Experimental Ward Unit was built by the Western Regional Hospital Board in conjunction with the Scottish Home and Health Department. This ward was opened for patients at the beginning of 1965 and has been the subject of several publications (Building Services Research Unit, Univ. Glasgow, 1968; Whyte, 1968; Baird and Whyte, 1969). The present account deals with its possible usefulness in reducing cross-infection.

\section{MATERIALS AND METHODS}

The surgical unit

The general surgical unit at Hairmyres Hospital consists of 3 wards served by one operating theatre. Two of these wards, a male and female open ward, are Emergency Medical Service (EMS) wards built during the Second World War and the third is the experimental ward unit. The operating theatre was built at the same time as the older EMS wards and does not possess a mechanical ventilation system. It is situated at ground level, as are the wards, and it is connected to them by a long corridor with a plentiful supply of fresh air. The wards are also separated by long corridors, and no airborne spread of infection was expected between the individual wards or between the wards and the operating theatre. The surgical unit has 107 beds, 6 of which are for the intensive care of patients.

The design of the experimental ward unit (see fig. 1). Male patients were accommodated in the four 5-bed rooms, female patients in the five 4-bed rooms, and 4 of 6 single-bed rooms were used for male or female patients as required, the other 2 being used by the Building Services Research Unit for purposes unrelated to the care of patients. The ward was studied under normal working conditions and no attempt was made to enforce exceptional discipline during the course of the experiment. This meant that ambulant patients were free to move around the whole ward area, but in practice the male and female patients rarely mixed.

All rooms for patients were on the periphery of the building and the ancillary-service rooms such as the kitchen, nurses' station, utility room and bathrooms were in the central core area of the building. Two special areas were also provided, one for treatment and the other for intensive care. The treatment room was in the core area and was used for the inspection and dressing of wounds. The intensive-care area was in one corner of the ward and consisted of a 4-bed room and 2 isolation rooms. It was available for patients from all three wards, but was little used because of shortage of staff.

The air-conditioning system of the experimental ward unit. Four independent zones of the ward (the treatment area, the intensive-care area, the patients' rooms and the central core area) were served separately by an air-conditioning plant. The air supplied to these four zones was filtered, humidified and either heated or cooled. The temperature in the ward area was set at $68^{\circ} \mathrm{F}\left(20^{\circ} \mathrm{C}\right)$ and the relative humidity at 55 per cent. The volumes of air supplied were to the ward area $7350 \mathrm{cu}$. $\mathrm{ft}$ per min. $\left(3.47 \mathrm{~m}^{3}\right.$ per s), to the treatment area $1000 \mathrm{cu}$. $\mathrm{ft}$ per min. $\left(0.47 \mathrm{~m}^{3}\right.$ per s), to the intensive-care area $3300 \mathrm{cu} . \mathrm{ft}$ per $\min .\left(1.56 \mathrm{~m}^{3}\right.$ 
per s) and to the central core $4000 \mathrm{cu}$. ft per min. $\left(1.89 \mathrm{~m}^{3}\right.$ per s). This represented 7-8 air changes per hr in the patients' rooms. Two-thirds of the ward air was recirculated through high-efficiency filters. This system is more fully described elsewhere (Building Services Research Unit, Univ, Glasgow). The bacterial efficiency of the air conditioning plant was thoroughly examined with regard to air filters, humidifiers and duct surfaces, and the bacterial content of the air supplied to the ward was found to be satisfactory (Whyte).

The design of the control open wards. The female ward was of the standard EMS pattern (fig. 2). Beds were provided for 29 patients, the air space per bed was about $1000 \mathrm{cu}$. $\mathrm{ft}$ $\left(28 \cdot 3 \mathrm{~m}^{3}\right)$ and the distance between bed centres was $7 \mathrm{ft}(2 \cdot 1 \mathrm{~m})$.

The male open ward, as shown in fig. 2, was an upgraded version of the basic EMS ward, the beds being arranged in bays constructed by partitions $7 \mathrm{ft}(2.13 \mathrm{~m})$ high. The ancillary rooms and toilet facilities were also reconstructed and a day-space was provided at the end of the ward. This ward had beds for 28 patients, and the air space per bed was about $1000 \mathrm{cu}$. ft $\left(28 \cdot 3 \mathrm{~m}^{3}\right)$.

There was no mechanical ventilation in either ward.

Distribution of patients and staff between the three wards. Hairmyres Hospital is a district hospital serving a new town and the surrounding countryside. The wards studied provided a general surgical service. Six beds in the female open ward and four beds in the experimental ward were used for female urological patients, male urological patients were treated elsewhere, and no orthopaedic or thoracic surgery was done. Patients (including emergency admissions) were received into both the open-plan wards on Tuesday, Thursday, Saturday and on alternate Sundays. The experimental unit received patients on the other days of the week. Although based in one ward, the surgeons did not confine their activities solely to that ward; the 3 wards were run as one unit with a great deal of interchange of staff. The whole surgical unit was in the charge of one nursing sister with other sisters in charge of individual wards. Nursing procedure and equipment was therefore basically similar

\section{Collection and examination of swabs}

Collection of nasal swabs. As soon as possible after the patient's admission into the ward the anterior nares were swabbed by a member of the nursing staff with a charcoal-coated swab, which was then stabbed into Stuart's transport medium (Oxoid) in a screw-capped bottle. Thereafter, nasal swabbing of all patients was carried out every Monday and Thursday, and dry sterile cottonwool swabs were used for this purpose. The swabs were collected between $6.00 \mathrm{a} . \mathrm{m}$. and $8.00 \mathrm{a} . \mathrm{m}$. and placed in the refrigerator until $9.00 \mathrm{a} . \mathrm{m}$. when they were taken to the laboratory for examination.

Examination of the nasal swabs. The nasal swabs were plated directly on to plates of phenolphthalein diphosphate agar (Barber and Kuper, 1951), which were incubated for $24 \mathrm{hr}$ at $37^{\circ} \mathrm{C}$ and then exposed to ammonia vapour. When bright pink phosphatase-positive colonies resembling Staph. aureus were present, 6-8 of them were subcultured into tubes of broth-plasma $(9: 1 \mathrm{v} / \mathrm{v})$. These tubes were examined at intervals up to $24 \mathrm{hr}$ and any showing coagulation were plated out on to phosphatase medium to check their purity. Their antibiotic sensitivity was tested on blood agar with disks containing the following amounts of antibiotic (in $\mu \mathrm{g}$ ): penicillin (1.5), tetracycline (10), neomycin (10), and cloxacillin (5). A subculture of each culture taken from outwith the zones of inhibition was inoculated on to a nutrient agar slope in a screw-capped bottle. Phage typing (Blair and Williams, 1961) was carried out with the basic set of phages obtained from the Staphylococcus Reference Laboratory, London.

\section{Other information obtained}

Clinical details. Note was made of the patients' age and sex, and details of operative treatment and antibiotic therapy were recorded.

Assessment of wound infection. A wound was regarded as infected (1) when pus was visible to the naked eye or (2) if a fluid exudate was present and pathogenic bacteria were isolated from it. All Staph. aureus cultures isolated from wounds or septic lesions were tested for antibiotic sensitivity and were phage typed. 
Nasal acquisition of Staph. aureus. The isolation of a strain of Staph. aureus not present in any previous swab was taken as evidence of an acquisition. Strains isolated successively from individual patients were compared, and differences in phage-typing pattern (Blair and Williams) or in antibiotic-resistance patterns were taken as evidence that a new strain had appeared. If there was any doubt about this the tests on the organisms were repeated. Acquisition was measured separately for (1) all acquisitions of Staph. aureus, (2) acquisitions of tetracycline-resistant strains and (3) acquisitions after the second swabbing (delayed acquisitions), and was expressed as the rate of acquisition per 100 patient-wk of exposure in the ward.

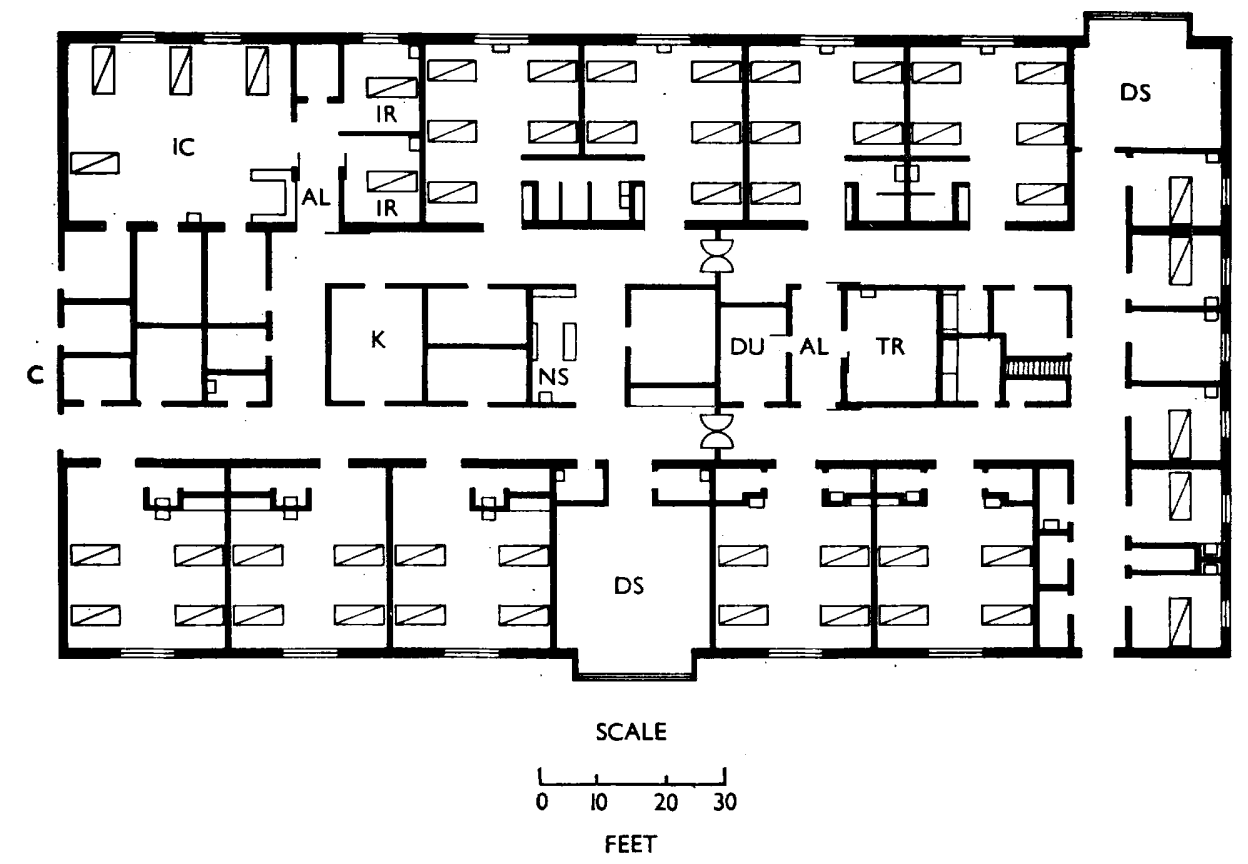

FIG. 1.-Diagram of the experimental ward unit.

$\square=\mathrm{Bed} ; \mathrm{IR}=$ isolation room; $\mathrm{TR}=$ treatment room; $\mathrm{AL}=$ air lock; $\mathrm{DU}=$ dirty utility: $\mathrm{DS}=$ day space; $\mathrm{K}=$ kitchen; $\mathrm{NS}=$ nurses' station; $\mathrm{C}=$ corridor; $\mathrm{IC}=$ intensive care.

\section{RESULTS}

Comparison of the patients in the experimental ward and in the two open-plan wards

Table I summarises information about the patients who were used to study the rate of nasal acquisition of Staph. aureus between 1 June 1966 and 1 Apr. 1967 , and compares the 800 patients in the experimental ward with the 926 patients in the two open-plan wards. The two groups were comparable in average age, in sex-composition, in the average length of stay in hospital, in the proportion staying longer than $2 \mathrm{wk}$ and in the proportion undergoing surgical operation, but rather more of the patients in the open wards (37 per cent.) than in the experimental ward ( 28 per cent.) received antibiotics while in hospital. 


\section{Nasal acquisition of Staph. aureus}

Comparisons were made of the number of acquisitions, and of the rate of acquisitions, in the two groups of patients, of all strains of Staph. aureus, of tetracycline-resistant strains, and of strains acquired after the second swabbing (delayed acquisitions). The rates were calculated separately for patients who stayed in the ward for $2 \mathrm{wk}$ or less, and for patients who stayed longer (table II).

THE MALE OPEN WARD

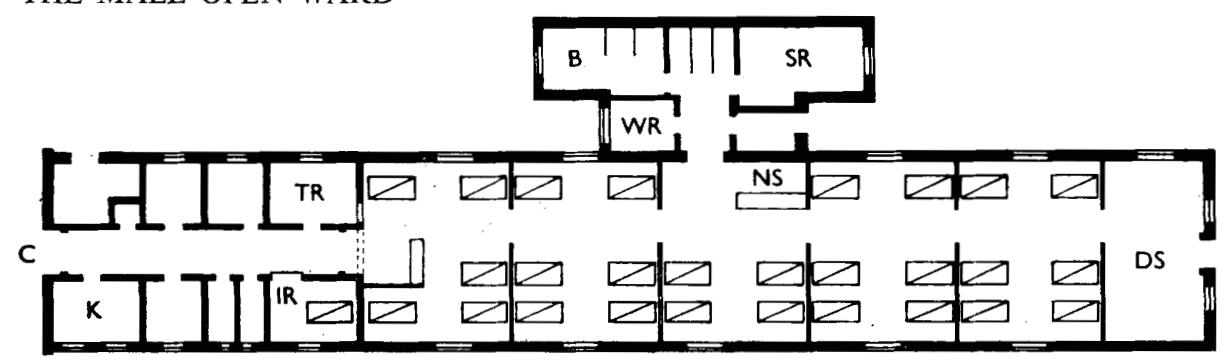

THE FEMALE OPEN WARD
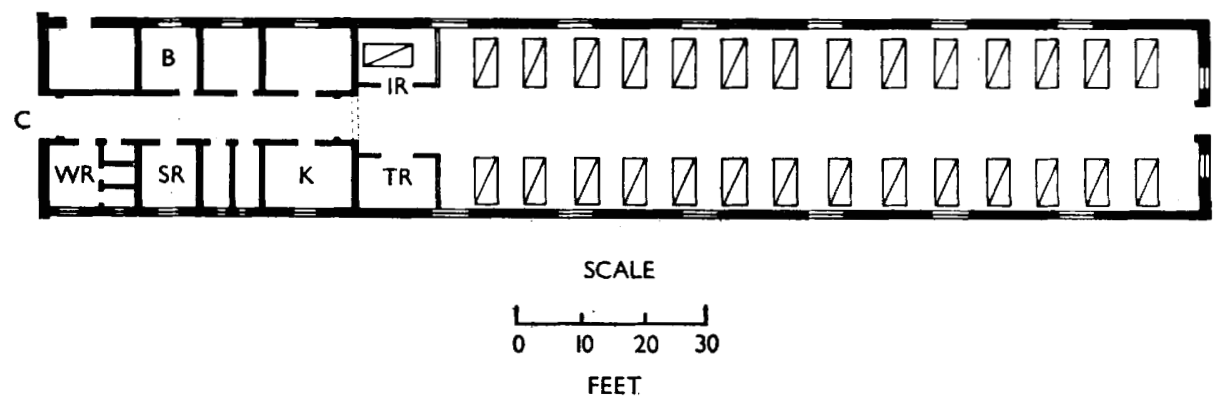

FIG. 2.-Diagram of the two open wards.

$\nabla=$ Bed; IR = isolation room; $T R=$ treatment room; $D S=$ day space; $S R=$ sluice room; $\mathrm{WR}=$ wash room; $\mathrm{B}=$ bathroom; $\mathrm{K}=$ kitchen; $\mathrm{NS}=$ nurses' station; $\mathrm{C}=$ corridor.

The rate of acquisition for all Staph. aureus in the experimental ward (10.6 per 100 patient-wk) was slightly lower than the rate in the open wards (12.4 per 100 patient-wk), and there appeared to be a larger difference in the rate of delayed acquisition ( 4.0 and 6.1 per 100 patient-wk respectively), but little difference in the rate of acquisition of tetracycline-resistant strains $(4 \cdot 1$ and 4.3 per 100 patient-wk respectively).

Differences between the acquisition rates of patients in the experimental ward and in the control wards were confined mainly to patients who stayed 2 wk or less in the ward. In these short-stay patients, all acquisitions occurred at a rate of 9.2 per 100 patient-wk in the experimental ward and 12.9 in the open wards. The rates for delayed acquisition were respectively 1.8 per 100 patient-wk and 6.3 per 100 patient-wk, but again there was no such difference in the rate of acquisition of tetracycline-resistant organisms. Patients who stayed longer than $2 \mathrm{wk}$ had little if any advantage in lower rates of acquisition in the experimental ward. 
In table III the rates of acquisition observed in the present study are compared with rates recorded in 4 previous studies, some obtained by once-weekly and some by twice-weekly swabbing. Our results were recalculated on the basis of once-weekly swabbing to facilitate comparison, and it will be seen that they are within the ranges found by other workers.

TABLE I

Comparison of the patients in the experimental ward with those in the two open wards

\begin{tabular}{l|c|c|c|c|c|c|c}
\hline & \multicolumn{7}{|c}{ Patients } \\
\cline { 2 - 7 } & $\begin{array}{c}\text { Total } \\
\text { number }\end{array}$ & $\begin{array}{c}\text { Average } \\
\text { age } \\
\text { (yr) }\end{array}$ & $\begin{array}{c}\text { Males } \\
\text { (per cent.) }\end{array}$ & $\begin{array}{c}\text { Average } \\
\text { length } \\
\text { of stay } \\
\text { (wk) }\end{array}$ & $\begin{array}{c}\text { Stayed } \\
\text { (w wk } \\
\text { (per cent.) }\end{array}$ & $\begin{array}{c}\text { Had } \\
\text { surgical } \\
\text { operation } \\
\text { (per cent.) }\end{array}$ & $\begin{array}{c}\text { Treated } \\
\text { with } \\
\text { antibiotics } \\
\text { (per cent.) }\end{array}$ \\
\hline In experimental ward & 800 & 38 & 46 & 1.99 & 71 & 51 & 28 \\
In open wards. & 926 & 38 & 45 & 1.94 & 67 & 56 & 37 \\
\hline
\end{tabular}

TABLE II

Nasal acquisition of Staphylococcus aureus by patients in the experimental ward and in the open wards

\begin{tabular}{|c|c|c|c|c|c|c|}
\hline & \multicolumn{6}{|c|}{ Number (and rate) of acquisitions by patients in } \\
\hline & \multicolumn{3}{|c|}{ experimental ward of } & \multicolumn{3}{|c|}{ open wards of } \\
\hline & $\begin{array}{l}\text { all } \\
\text { Staph. } \\
\text { aureus }\end{array}$ & $\begin{array}{l}\text { tetracycline- } \\
\text { resistant } \\
\text { Staph. } \\
\text { aureus }\end{array}$ & $\begin{array}{c}\text { Staph. } \\
\text { aureus } \\
\text { after 2nd } \\
\text { swabbing } \dagger\end{array}$ & $\begin{array}{l}\text { all } \\
\text { Staph. } \\
\text { aureus }\end{array}$ & $\begin{array}{l}\text { tetracycline- } \\
\text { resistant } \\
\text { Staph. } \\
\text { aureus }\end{array}$ & $\begin{array}{c}\text { Staph. } \\
\text { aureus } \\
\text { after 2nd } \\
\text { swabbing } \dagger\end{array}$ \\
\hline By all patients . & $169(10 \cdot 6)^{*}$ & $65(4 \cdot 1)$ & $64(4 \cdot 0)$ & $223(12 \cdot 4)$ & $77(4 \cdot 3)$ & $109(6 \cdot 1)$ \\
\hline $\begin{array}{l}\text { By patients who stayed } \\
\leq 2 \mathrm{wk}\end{array}$ & $55(9 \cdot 2)$ & $14(2 \cdot 3)$ & $11(1 \cdot 8)$ & $84(12 \cdot 9)$ & $16(2 \cdot 5)$ & $36(5 \cdot 5)$ \\
\hline $\begin{array}{l}\text { By patients who stayed } \\
>2 \text { wk }\end{array}$ & $114(11 \cdot 4)$ & $51(5 \cdot 1)$ & $53(5 \cdot 3)$ & $139(12 \cdot 1)$ & $61(5 \cdot 3)$ & $73(6 \cdot 3)$ \\
\hline
\end{tabular}

* Acquisitions per 100 patient-wk. $†$ Delayed acquisitions (see text).

Change in nasal carriage of Staph. aureus with length of stay in hospital

Fig. 3 shows the percentage of carriers of all Staph. aureus strains, and of strains classified according to their antibiotic resistance, by patients in the experimental ward and the open wards, on admission and during subsequent half-weeks of stay. The $4 \frac{1}{2}$-wk and the 5 -wk samples were combined because of their small size. 
In the experimental ward the nasal carriage rate of patients on admission was 42.9 per cent. for all Staph. aureus, 5.8 per cent. for tetracycline-resistant strains, 19.4 per cent. for penicillin-resistant strains and 17.7 per cent. for strains sensitive to antibiotics. After a period of between $4 \frac{1}{2}$ and $5 \mathrm{wk}$ the nasal

\section{TABLE III}

Comparison of rates of nasal acquisition of Staphylococcus aureus observed in various studies

\begin{tabular}{|c|c|c|c|c|c|c|}
\hline \multirow{3}{*}{ Author and type of ward studied } & & \multirow{3}{*}{$\begin{array}{l}\text { Number } \\
\text { of } \\
\text { patients } \\
\text { studied }\end{array}$} & \multicolumn{4}{|c|}{ Acquisitions per 100 patient-wk } \\
\hline & & & \multicolumn{2}{|c|}{$\begin{array}{c}\text { weekly } \\
\text { swabbing }\end{array}$} & \multicolumn{2}{|c|}{$\begin{array}{l}\text { twice-weekly } \\
\text { swabbing }\end{array}$} \\
\hline & & & All* & $\mathrm{T} \dagger$ & All & $\mathbf{T}$ \\
\hline $\begin{array}{l}\text { Shooter } \text { et al. }(1963) \\
\text { Divided surgical ward } \\
\text { Pre-operative ward (with isolation) } \\
\text { Post-operative (no segregation) }\end{array}$ & : & $\begin{array}{l}276 \\
136\end{array}$ & $\begin{array}{r}9 \cdot 9 \\
11 \cdot 9\end{array}$ & $\begin{array}{l}2 \cdot 0 \\
4 \cdot 2\end{array}$ & $\begin{array}{l}\cdots \\
\cdots\end{array}$ & $\begin{array}{l}\ldots \\
\cdots\end{array}$ \\
\hline $\begin{array}{l}\text { PHLS Medical Wards Survey (quoted by } \\
\text { et al., 1965) } \\
\text { Patient treated with antibiotics } \\
\text { Patient not treated with antibiotics }\end{array}$ & $\begin{array}{l}\text { Parker } \\
. \\
.\end{array}$ & 4100 & $\begin{array}{l}9 \cdot 4 \\
9 \cdot 0\end{array}$ & $\begin{array}{l}6 \cdot 3 \\
3 \cdot 7\end{array}$ & $\begin{array}{l}\cdots \\
\cdots\end{array}$ & $\begin{array}{l}\cdots \\
\cdots\end{array}$ \\
\hline $\begin{array}{l}\text { Parker } \text { et al. }(1965) \\
\text { Infectious disease hospital } \\
\quad \text { (cubicalisation and barrier nursing) }\end{array}$ & . & 468 & $6 \cdot 4$ & $1 \cdot 4$ & $10 \cdot 0$ & $2 \cdot 1$ \\
\hline $\begin{array}{l}\text { idwell et al. (1966) } \\
\text { Subdivided thoracic surgery ward }\end{array}$ & . & 714 & $3 \cdot 4$ & $1 \cdot 3$ & $\ldots$ & $\ldots$ \\
\hline $\begin{array}{l}\text { S"his tudy } \\
\text { Subdivided general surgical ward } \\
\text { Open general surgical wards }\end{array}$ & : & $\begin{array}{l}800 \\
926\end{array}$ & $\begin{array}{l}7 \cdot 0 \\
8 \cdot 4\end{array}$ & $\begin{array}{l}2 \cdot 9 \\
3 \cdot 2\end{array}$ & $\begin{array}{l}10 \cdot 6 \\
12 \cdot 4\end{array}$ & $\begin{array}{l}4 \cdot 1 \\
4 \cdot 3\end{array}$ \\
\hline
\end{tabular}

* All = All strains of Staphylococcus aureus.

$\dagger \mathbf{T}=$ Tetracycline-resistant strains of Staphylococcus aureus only.

carriage rate was 44.9 per cent. for all strains, 25.4 per cent. for tetracyclineresistant strains, 11.2 per cent. for penicillin-resistant strains and 8.3 per cent. for sensitive strains. In the combined open wards the nasal carriage rate of patients on admission was 39.8 per cent. for all Staph. aureus, 4.4 per cent. for tetracycline-resistant strains, 19.0 per cent. for penicillin-resistant strains and 16.4 per cent. for sensitive strains. After the same period of between $4 \frac{1}{2}$ and $5 \mathrm{wk}$ the nasal carriage rates were 40 per cent. for all strains, 22.0 per cent. for tetracycline-resistant organisms, 10.6 per cent. for penicillin-resistant strains and 8.1 per cent. for sensitive strains. 


\section{Wound sepsis}

The incidence of wound sepsis in the experimental ward and in the two open wards was recorded during a period of $12 \mathrm{mth}$. In all, 1080 operations were performed, 919 of them during the time when nasal acquisition was being
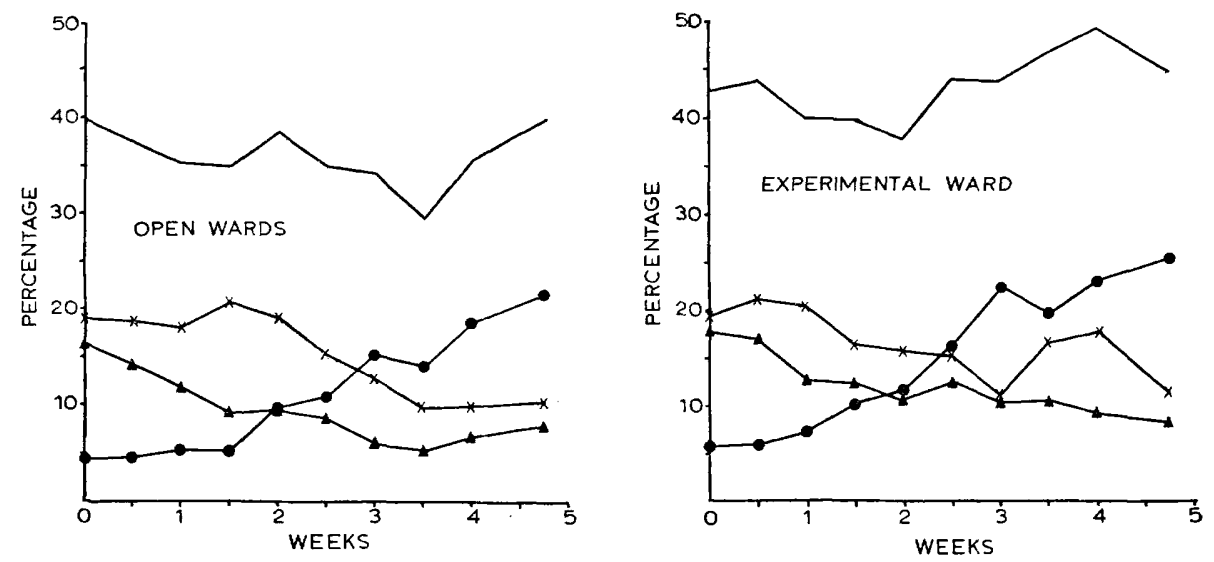

FIG. 3. - Nasal carriage of Staphylococcus aureus by patients during each half-week of stay in the experimental ward and the open wards. $-=$ All strains of Staph. aureus, $--1-=$ strain: sensitive to all antibiotics used, $-\times-=$ strains resistant to penicillin, $-\square$ strain: resistant to tetracycline.

TABLE IV

Wound sepsis in the experimental ward and in the open wards

\begin{tabular}{|c|c|c|c|}
\hline \multirow{3}{*}{ Patients } & \multicolumn{3}{|c|}{ Wound sepsis rate (ratio* and percentage) } \\
\hline & \multirow{2}{*}{$\begin{array}{l}\text { All wound } \\
\text { sepsis }\end{array}$} & \multicolumn{2}{|c|}{$\begin{array}{c}\text { Acquired Staphylococcus aureus } \\
\text { sepsis } \dagger\end{array}$} \\
\hline & & Total & $\begin{array}{l}\text { In patients } \\
\text { staying } \\
\leqq 2 \mathrm{wk}\end{array}$ \\
\hline In experimental ward & $79 / 465(17 \cdot 0)$ & $25 / 446(5 \cdot 6)$ & $7 / 280(2 \cdot 5)$ \\
\hline In open wards & $80 / 615(13 \cdot 0)$ & $21 / 587(3 \cdot 6)$ & $3 / 290(1 \cdot 0)$ \\
\hline
\end{tabular}

* Number of cases of sepsis/number of operations.

$\dagger$ Excluding operations for abscesses and other septic conditions.

studied and the remainder in the preceding $2 \mathrm{mth}$. The total sepsis rate was expressed as a proportion of all operations performed, but the rate of acquired sepsis due to Staph. aureus was related to operations other than those for the treatment of abscesses or similar septic lesions.

The total amount of wound sepsis (table IV) was greater in the experimental ward ( 17.0 per cent.) than in the open ward (13.0 per cent.), but the difference was not statistically significant $\left(\chi^{2}=3.34, P>0.05\right)$. The rate of acquired 
Staph. aureus sepsis was 3.6 per cent. in the two open wards compared with 5.6 per cent. in the experimental ward. This difference was also not statistically significant $\left(\chi^{2}=2 \cdot 45, \mathrm{P}>0.05\right)$. The figures for staphylococcal sepsis among patients who stayed for $2 \mathrm{wk}$ or less were too small for reliable comparison, but there was no indication of any advantage for patients in the experimental ward to correspond to their lower rate of nasal acquisition of Staph. aureus.

\section{Discussion}

One difficulty in the interpretation of our results arose from the fact that the experimental unit was a single ward containing both male and female patients and the control unit consisted of separate wards of male and female patients. The wards varied somewhat in function because of the particular interests of the surgeon-in-charge, but there was little difference between the experimental and the control unit in the type of patient received, the operations performed and the length of stay of the patients.

In the comparison of the rates of nasal acquisition of Staph. aureus between the different wards separate consideration was given to the acquisition of (i) all strains of Staph. aureus, (ii) strains resistant to tetracycline and (iii) strains acquired after the second swabbing (delayed acquisitions). Strains resistant to tetracycline are generally considered to be of hospital origin, and delayed acquisitions may also be considered to be a strong indication of cross-infection, because a single negative nasal culture is not a very reliable index of the absence of Staph. aureus. Consideration of the two latter indices lessens the possibility of being misled by spurious acquisitions when either (i) an organism resident in the patient's nose is not isolated from an admission swab but is isolated subsequently or (ii) the inherent inaccuracies of phage typing suggest an apparent acquisition, but the second organism is only a variant of the original strain.

The rate of acquisition of all strains of Staph. aureus was slightly lower in the experimental than in the control wards, and the difference was somewhat more obvious when delayed acquisitions were considered. This advantage appeared to be restricted to patients who stayed in the experimental ward for 2 wk or less. It was notable, however, that there was no significant difference between the experimental and the control wards in the rate of acquisition of tetracycline-resistant strains, which might have been expected to be a very specific index of hospital-acquired nasal colonisation.

To exclude the influence of imperfectly controlled variables on these results, the effects of antibiotic treatment, surgical operation, length of stay and age of patients on acquisition of Staph. aureus were compared for male and female patients in the test and control units. The analysis of these results, which failed to show any significant difference between the two units, is available on request to the authors.

A comparison of our results and those of others (table III) showed that the rate of nasal acquisition in our experimental and control wards was intermediate between rates observed previously in open-plan wards and subdivided wards. They exceeded the low rate of acquisition found in patients in isolation cubicles 
(Parker et al., 1965) or in a subdivided thoracic surgery ward (Lidwell et al.; 1966), but were considerably lower than those observed elsewhere in open medical and surgical wards (Shooter et al., 1963; Parker et al.).

The rapidity with which resistant strains of Staph. aureus replace sensitive strains in the nasal flora has been suggested as a possible index of the efficiency of a hospital design in protecting patients from cross-infection (Parker et al.; Lidwell et al.; Williams, 1967). A comparison of the carriage-rates of strains of Staph. aureus with different antibiotic-sensitivity patterns during successive weeks of stay in the experimental ward and the open wards failed to show any distinct difference.

Wound sepsis, and acquired wound sepsis due to Staph. aureus, were somewhat more frequent in the experimental ward than in the open-plan ward, but the difference was not statistically significant.

The conclusions may therefore be drawn that although the design of the experimental ward may have been responsible for some reduction in the rate of nasal colonisation with Staph. aureus, the benefit was restricted to patients who stayed in the ward for 2 wk or less, and there was no significant change in the pattern of nasal colonisation by resistant staphylococci; and that this difference was not matched by any decrease in the amount of post-operative wound sepsis. It was therefore concluded that although there may be a marginal advantage in this new type of ward in respect of the nasal acquisition of Staph. aureus this is of little practical importance in a general surgical unit.

\section{SUMMARY}

Observations were made on patients in a new type of subdivided hospital ward with controlled ventilation and in two older open-plan wards with natural ventilation.

The rate of acquisition in the nose of new strains of Staph. aureus was somewhat lower in the new ward than in the old wards, but the advantage was restricted to patients who stayed $2 \mathrm{wk}$ or less, and there was no corresponding reduction in the rate of acquisition of tetracycline-resistant staphylococci or in the proportion of patients who became carriers of resistant strains.

No evidence was obtained that the risk of post-operative wound sepsis. or of acquired sepsis due to Staph. aureus, was less in the new ward than in the old wards.

We thank Professor R. G. White and Mr W. Carson, leader of the Building Services Research Unit, for their assistance and encouragement, Mrs C. Low and Mrs A. T. O'Niel for technical assistance and Mrs J. Gemmell for clerical assistance. We also wish to thank Mr K. I. Macrosson, senior surgeon at Hairmyres Hospital, and the staff of the wards we studied, and particularly Sister M. F. B. Muir, who was of great assistance in the collection of clinical details.

This study was sponsored by the Scottish Home and Health Department.

\section{REFERENCES}

BAIRD, G., AND Whyte, W. . . . . 1969. J. Hyg., Camb., 67, 507.

BARber, MARY, AND KuPer, S. W. A. . 1951. J. Path. Bact., 63, 65. 
Blair, J. E., And Williams, R. E. O. 1961. Bull. Wld Hlth Org., 24, 771.

Blowers, R., Mason, G. A., Wallace, 1955. Lancet, 2, 786.

K. R., AND WALTON, M.

Bourdillon, R. B., AND Colebrook, L. 1946. Ibid., 1, 561.

Building Services Research Unit, 1968. Report.

UNIV. GLASGOW

Colebrook, L., Gibson, T., Todd, J. P., 1944. Spec. Rep. Ser. Med. Res. Coun., no. 249. Clark, A. M., Brown, A., AND ANDERSON, A. B.

Lidwell, O. M., Polakoff, Sheila, 1966. J. Hyg., Camb., 64, 321. Jevons, M. Patricia, Parker, M. T., Shooter, R. A., French, Valentine I., AND DUNKERLEY, D. R.

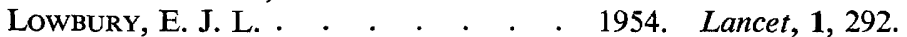

Parker, M. T., John, Madeleine, 1965. Br. Med. J., 1, 1101. EMOND, R. T. D., AND MACHACEK, K. A.

Shooter, R. A., TAylor, G. W., Ellis, 1956. Surg. Gynec. Obstet., 103, 257. G., AND Ross, J. P.

Shooter, R. A., Thom, B. T., Dunker- 1963. Br. Med. J., 2, 1567. ley, D. R., TAylor, G. W., Parker, M. T., JOHN, MADELEINE, AND RICHARDS, I. D. G.

Steingold, L., Dunn, L., Hawksworth, 1963. J. Appl. Bact., 26, 435. E., AND LIMB, L.

WhYTE, W. . .

Williams, R. E. O.. . . . . . . 1967. Ibid., 65, 207.

Willuams, R. E. O., Noble, W. C., 1962. Br. Med. J., 2, 275. Jevons, M. Patricia, Lidwell, O. M., Shooter, R. A., White, R. G., Thom, B. T., AND TAYLOR, G. W.

WoOdruff, M. F. A., Nolan, B., 1968. Lancet, 1, 905. BowIE, J. H., AND Gould, J. C. 